\begin{tabular}{ll|l} 
Case Reports in & \multicolumn{2}{c}{ Case Rep Gastroenterol 2013;7:75-81 } \\
\cline { 2 - 3 } Gastroenterology & $\begin{array}{l}\text { DOI: 10.1159/000348761 } \\
\text { Published online: March 1, 2013 }\end{array}$ & $\begin{array}{l}\text { ○ 2013 S. Karger AG, Basel } \\
1662-0631 / 13 / 0071-0075 \$ 38.00 / 0 \\
\text { www.karger.com/crg }\end{array}$ \\
\hline & $\begin{array}{l}\text { This is an Open Access article licensed under the terms of the Creative Commons Attribution- } \\
\text { NonCommercial-NoDerivs 3.0 License (www.karger.com/OA-license), applicable to the } \\
\text { online version of the article only. Distribution for non-commercial purposes only. }\end{array}$
\end{tabular}

\title{
Transileocolic Vein Obliteration for Bleeding Rectal Varices with Portal Thrombus
}

\author{
Hirotaka Arai Takeshi Kobayashi Daichi Takizawa Mitsuo Toyoda \\ Hisashi Takayama Takehiko Abe \\ Department of Gastroenterology, Maebashi Red Cross Hospital, Maebashi, Japan
}

\section{Key Words}

Transileocolic vein obliteration $\cdot$ Rectal varices $\cdot$ Portal thrombus

\begin{abstract}
We report a case of rectal varices treated successfully with transileocolic vein obliteration (TIO). A 70-year-old man was admitted to our hospital for evaluation of fresh bloody stools in January 2011. Emergent colonoscopy revealed fresh blood in the rectum and tortuous rectal varices. Three-dimensional computed tomography was used as a non-invasive method for the identification of rectal varices and thrombus in the extrahepatic portal vein. Angiography demonstrated that rectal varices were supplied with backward blood flow by the inferior mesenteric vein. Transileocolic variceal obliteration was performed using coils and $5 \%$ ethanolamine oleate with iopamidol. Complete hemostasis was achieved without complications. We conclude that TIO is a safe and effective hemostatic measure for ruptured rectal varices with portal thrombus.
\end{abstract}

\section{Introduction}

A variety of collateral vascular routes, represented by gastroesophageal varices, occur in patients with portal hypertension. Ectopic varices outside the gastroesophageal lesion are relatively rare. The most common ectopic varices in patients with portal hypertension are reportedly rectal varices $[1,2]$. Bleeding from rectal varices is often fetal because the rapid and abundant blood flow can make it difficult to achieve hemostasis [3, 4].

Currently, various therapies, including endoscopic procedures [5-7], surgery [8] and direct therapeutic intervention [9-12], are available for the treatment of rectal varices. Interventional therapy for rectal varices is classified as transjugular intrahepatic portosys-

Hirotaka Arai, MD

Department of Gastroenterology, Maebashi Red Cross Hospital

3-21-36 Asahi-cho, Maebashi, Gunma 371-0014 (Japan)

E-Mail h-arai@maebashi.jrc.or.jp 
Arai et al.: Transileocolic Vein Obliteration for Bleeding Rectal Varices with Portal Thrombus

temic shunt [9] and transcatheter embolotherapy [10-12]. However, the optimal strategy for the eradication of rectal varices has not been established yet. In the case of rectal varices, the feeding and drainage vessels are the inferior mesenteric vein (IMV) and the internal iliac vein, respectively [2]. This hemodynamic characteristic of rectal varices prompted us to postulate that transcatheter embolotherapy through the IMV could be an effective therapeutic approach to eradicate the varices. Transileocolic vein obliteration (TIO) is an anterograde embolization of collateral feeding vessels via the portal vein, using a sclerosing agent. We report a case of rectal varices with portal thrombus successfully treated with TIO.

\section{Case Report}

A 70-year-old man was admitted to our hospital for evaluation of fresh bloody stools in January 2011. He had been suffering from alcoholic liver cirrhosis with esophageal varices. He had been treated endoscopically for esophageal varices three times from 2005 to 2007.

Physical examination on admission showed the patient to be alert. His blood pressure was $86 / 57 \mathrm{~mm} \mathrm{Hg}$ and his heart rate was $50 / \mathrm{min}$. The palpebral conjunctiva showed anemia, and the bulbar conjunctiva was not icteric. No abnormalities were noted on cardiac and respiratory examination. Ascites and pitting edema of the lower extremities were not present. Neurologic examination was normal.

Emergent colonoscopy revealed fresh blood in the rectum and tortuous rectal varices. Upper gastrointestinal endoscopy revealed no esophagogastric varices. Three-dimensional computed tomography (3D-CT) was used as a non-invasive method for the identification of rectal varices and thrombus in the extrahepatic portal vein (fig. 1, fig. 2). Angiography demonstrated that the rectal varices were supplied with backward blood flow by the IMV and drained into the internal iliac vein.

TIO was performed using coils and $50 \mathrm{~g} / \mathrm{l}$ ethanolamine oleate (EO) solution with iopamidol (50 g/l EO), which contained equal amounts of $100 \mathrm{~g} / \mathrm{l} \mathrm{EO} \mathrm{(Grela,} \mathrm{Tokyo,} \mathrm{Japan)} \mathrm{and}$ iopamidol 300 (Schering, Berlin, Germany), to obliterate the varices. Briefly, a right pararectal skin incision was made to expose the ileocolic vein and its marginal vein. The marginal vein was punctured and an occlusion balloon catheter was inserted into the IMV via the ileocolic and superior mesenteric veins under radiologic guidance. After blood flow had been occluded by balloon inflation, anterograde venography was performed through the balloon catheter (fig. 3). When rectal varices were visualized and retention of the contrast medium in the rectal varices was identified, a microcatheter was advanced into the feeding vessel and $20 \mathrm{ml}$ of $50 \mathrm{~g} / \mathrm{l} \mathrm{EO}$, as a sclerosant, was slowly injected in the antegrade direction into the rectal varices through the microcatheter under fluoroscopy. When varices could be shown in their entirety, injection was suspended. After the sclerosant had remained in place for $1 \mathrm{~h}$ to allow thrombus formation, the hemolyzed blood and excess uncoagulated sclerosant were collected through the catheter. Then the microcoils were used to embolize the remaining feeding vein and to stabilize the thrombus in rectal varices. Portography was repeated to assess obliteration of the feeding veins and the absence of flow to the rectal varices before removing the catheters.

Complete hemostasis was achieved without complications. Colonoscopy showed that the rectal varices had changed in color from red to blue. 3D-CT showed no blood flow inside the rectal varices. After this treatment, the patient suffered no further episodes of bleeding from rectal varices. 
Arai et al.: Transileocolic Vein Obliteration for Bleeding Rectal Varices with Portal Thrombus

\section{Discussion}

The first report of rectal varices was published in 1954 [13]. Rectal and pararectal varices reportedly develop in $44 \%$ of patients with portal hypertension [1]. There are reports describing the bleeding of rectal varices after endoscopic therapy for esophageal varices $[2$, 14 , 15]. Aggravation of rectal varices due to this therapy for esophageal varices was recognized to result from elevated portal pressure. In our case, the patient had undergone endoscopic therapy for esophageal varices 4 years previously. Since the obliteration of esophageal varices by endoscopic therapy could enhance portal flow through the IMV-iliac venous system, the incidental risk of rectal varices seems to be increased after eradication of esophageal varices. Moreover, since the thrombus in the extrahepatic portal vein produces strong pressure on the IMV, rectal varices might develop.

Various therapeutic procedures, including endoscopic variceal ligation $[5,6]$, endoscopic injection sclerotherapy [7], surgery [8], transjugular intrahepatic portosystemic shunt [9] and interventional embolotherapy [10-12], have been reported for treatment of rectal varices. There are reports on successful embolotherapy strategies for rectal varices using double balloon-occluded embolotherapy [10], percutaneous transhepatic obliteration (PTO) with sclerosant [11], and balloon-occluded retrograde transvenous obliteration [12]. In our case, balloon-occluded retrograde transvenous obliteration was not attempted because of multiple drainage vessels. We selected the TIO procedure rather than the PTO procedure because of the presence of portal thrombus. TIO is an anterograde embolization of collateral feeding vessels via the portal vein, using a sclerosing agent. While only the liver is punctured in the PTO procedure, the TIO procedure requires a pararectal skin incision to expose the ileocolic vein. Therefore, TIO is more invasive than PTO. We believe the indication for the TIO procedure to be rectal varices not treatable by the PTO procedure, such as the presence of portal thrombus.

Determination of the hemodynamics of rectal varices in each patient is important for selecting the most appropriate, endoscopic, surgical or radiological treatment. CT is a valuable technique for evaluating the presence of rectal varices, including both rectal wall and pararectal varices [16]. In our case, 3D-CT scans of the abdomen and pelvis were used to non-invasively identify rectal varices and thrombus in the extrahepatic portal vein. 3D-CT is a valuable technique for examining patients with portal hypertension as it enables rapid and accurate evaluation of the abdomen, including the presence and location of rectal varices and the evaluation of therapeutic effects.

We conclude that TIO is a safe and effective hemostatic measure for ruptured rectal varices with portal thrombus. Further experience is required to confirm the effectiveness and safety of this procedure for the treatment of rectal varices.

\section{Disclosure Statement}

The authors have no financial disclosures to make. 
Arai et al.: Transileocolic Vein Obliteration for Bleeding Rectal Varices with Portal Thrombus

\section{References}

1 Hosking SW, Smart HL, Johnson AG, et al: Anorectal varices, hemorrhoids, and portal hypertension. Lancet 1989;18:349-352.

2 Watanabe N, Toyonaga A, Kojima S, et al: Current status of ectopic varices in Japan: results of a survey by the Japan Society for portal hypertension. Hepatol Res 2010;40:763-776.

-3 Johansen K, Bardin J, Orloff MJ: Massive bleeding from hemorrhoidal varices in portal hypertension. JAMA 1980;244:2084-2085.

4 Herman BE, Baum S, Denobile J, et al: Massive bleeding from rectal varices. Am J Gastroenterol 1993;88: 939-942.

-5 Levine J, Tahiri A, Banerjee B: Endoscopic ligation of bleeding rectal varices. Gastrointest Endosc 1993;39: 188-190.

6 Shudo R, Yazaki Y, Sakurai S, et al: Endoscopic variceal ligation of bleeding rectal varices. Dig Endosc 2000;12:366-368.

7 Wang M, Desigan G, Dunn D: Endoscopic sclerotherapy for bleeding rectal varices. Am J Gastroenterol 1985;80:779-780.

8 Wilson SE, Stone RT, Christie JP, et al: Massive lower gastrointestinal bleeding from intestinal varices. Arch Surg 1979;114:1158-1161.

9 Katz JA, Rubin RA, Cope C, et al: Recurrent bleeding from anorectal varices: successful treatment with a transjugular intrahepatic portosystemic shunt. Am J Gastroenterol 1993;88:1104-1107.

10 Kimura T, Haruta I, Isobe Y, et al: A novel therapeutic approach for rectal varices: a case report of rectal varices treated with double balloon-occluded embolotherapy. Am J Gastroenterol 1997;92:883-886.

11 Okazaki H, Higuchi K, Shiba M, et al: Successful treatment of giant rectal varices by modified percutaneous transhepatic obliteration with sclerosant: report of a case. World J Gastroenterol 2006;12:5408-5411.

12 Watanabe $\mathrm{K}$, Imai $\mathrm{Y}$, Takayama $\mathrm{H}$, et al: A case of liver cirrhosis due to hepatitis $\mathrm{C}$ virus infection complicating giant anorectal varices treated with balloon-occluded retrograde transvenous obliteration. Clin J Gastroenterol 2011;4:19-23.

13 Case records of the Massachusetts general hospital, case 40102. N Engl J Med 1954;250:434-438.

14 Foutch PG, Sivak MV Jr: Colonic variceal hemorrhage after endoscopic injection sclerosis of esophageal varices. Am J Gastroenterol 1984;79:756-760.

15 Katakura K, Irisawa A, Obara K, et al: Appearance of rectal varices in extrahepatic portal obstruction after treatment for esophago-gastric varices. Fukushima J Med Sci 2002;48:51-56.

16 Levine CD, Gonzales RN, Wachsberg RH: CT evaluation of pararectal varices. J Comput Assist Tomogr 1997;21:992-995. 


\begin{tabular}{|c|c|c|}
\hline \multirow{3}{*}{$\begin{array}{r}\text { Case Reports in } \\
\text { Gastroenterology }\end{array}$} & \multirow{2}{*}{\multicolumn{2}{|c|}{ Case Rep Gastroenterol 2013;7:75-81 }} \\
\hline & & \\
\hline & DOI: $\underline{10.1159 / 000348761}$ & $\begin{array}{l}\text { (c) } 2013 \text { S. Karger AG, Basel } \\
\text { www.karger.com/crg }\end{array}$ \\
\hline
\end{tabular}

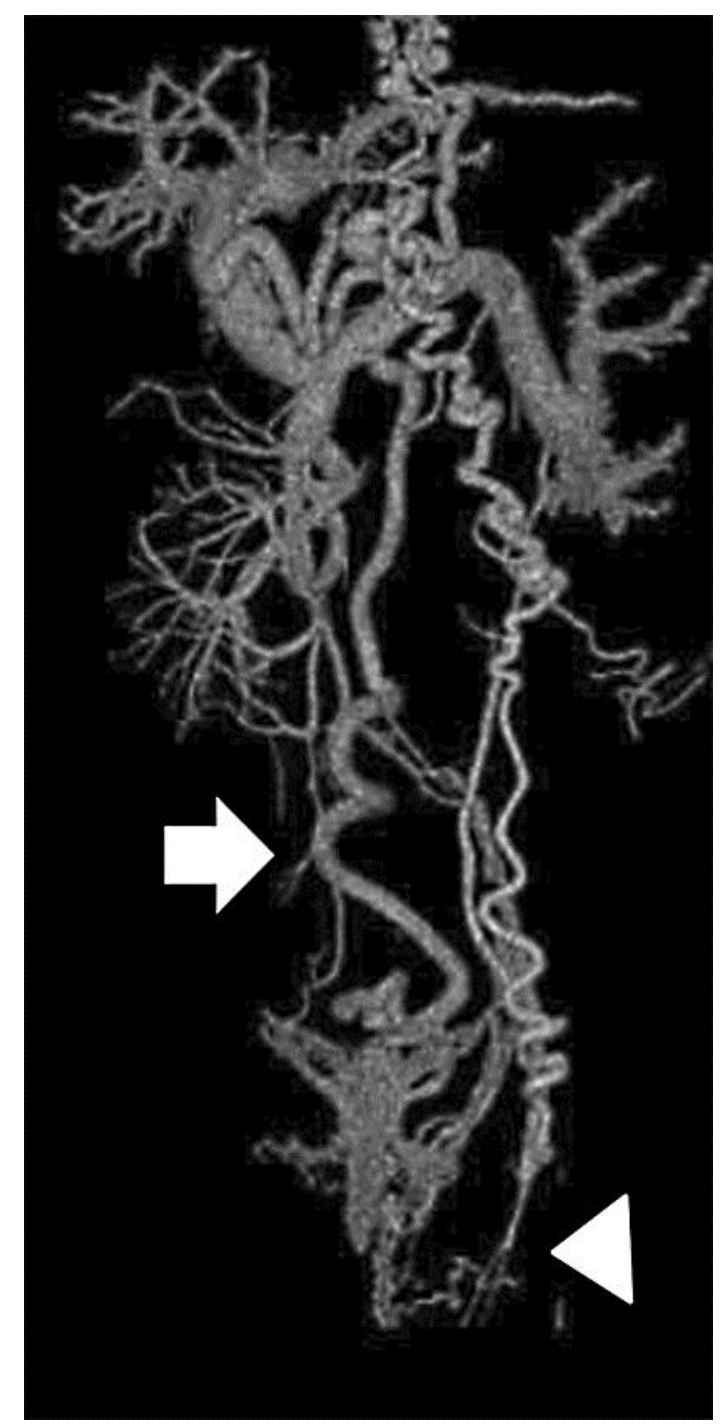

Fig. 1. On 3D-CT, the IMV (arrow) and internal iliac vein (arrowhead) are identifiable as the feeding and drainage vessels, respectively, of the rectal varices. 


\begin{tabular}{|c|c|c|}
\hline \multirow{3}{*}{$\begin{array}{r}\text { Case Reports in } \\
\text { Gastroenterology }\end{array}$} & \multirow{2}{*}{\multicolumn{2}{|c|}{ Case Rep Gastroenterol 2013;7:75-81 }} \\
\hline & & \\
\hline & DOI: $\underline{10.1159 / 000348761}$ & $\begin{array}{l}\text { (c) } 2013 \text { S. Karger AG, Basel } \\
\text { www.karger.com/crg }\end{array}$ \\
\hline
\end{tabular}

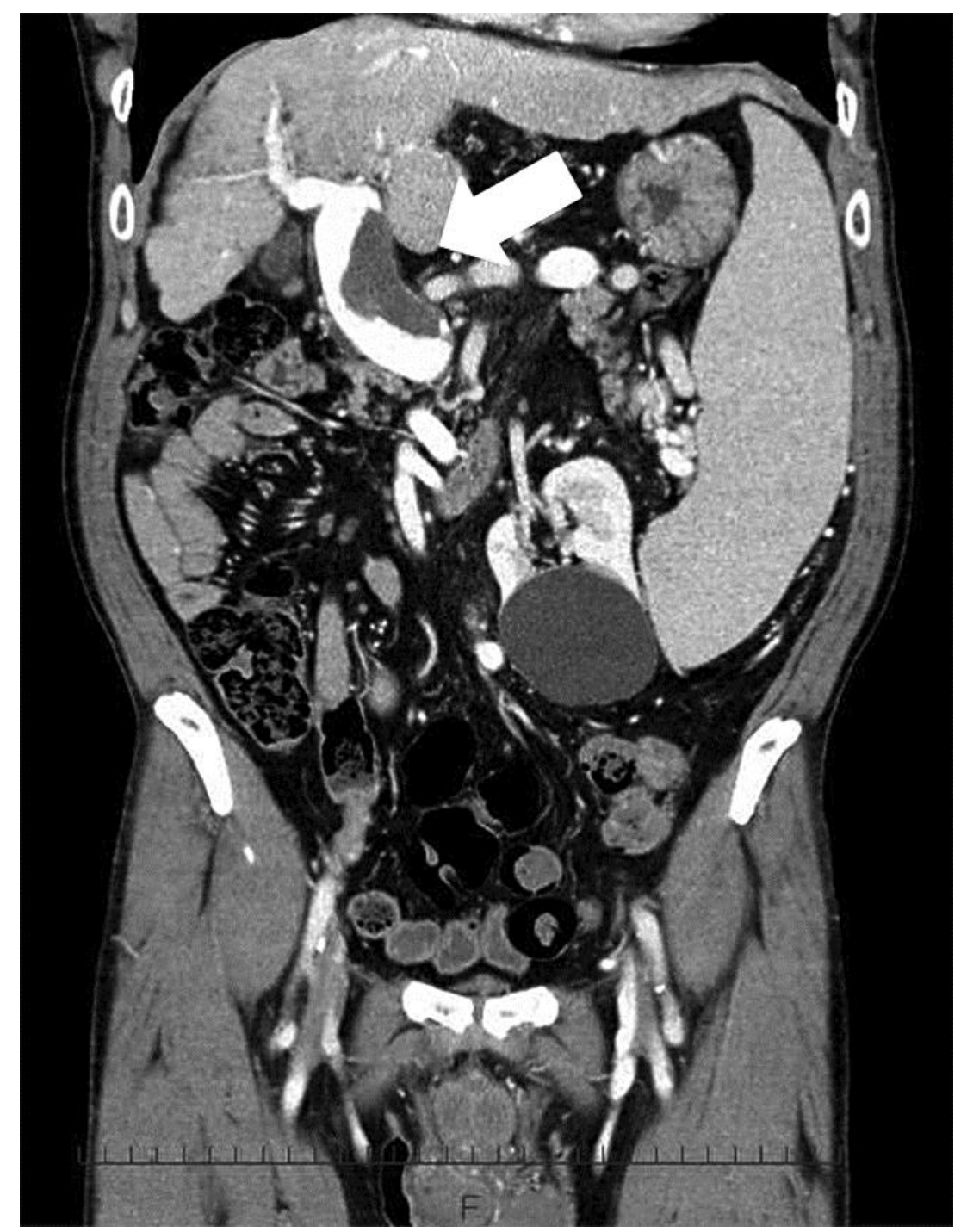

Fig. 2. Thrombus formation (arrow) inside the portal vein is seen on contrast-enhanced CT. 


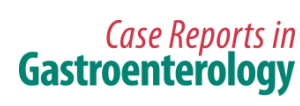

\begin{tabular}{l|l}
\hline \multicolumn{2}{l}{ Case Rep Gastroenterol 2013;7:75-81 } \\
\hline DOI: $\underline{10.1159 / 000348761}$ & $\begin{array}{l}\text { C 2013 S. Karger AG, Basel } \\
\text { www.karger.com/crg }\end{array}$ \\
\hline
\end{tabular}

Arai et al.: Transileocolic Vein Obliteration for Bleeding Rectal Varices with Portal Thrombus

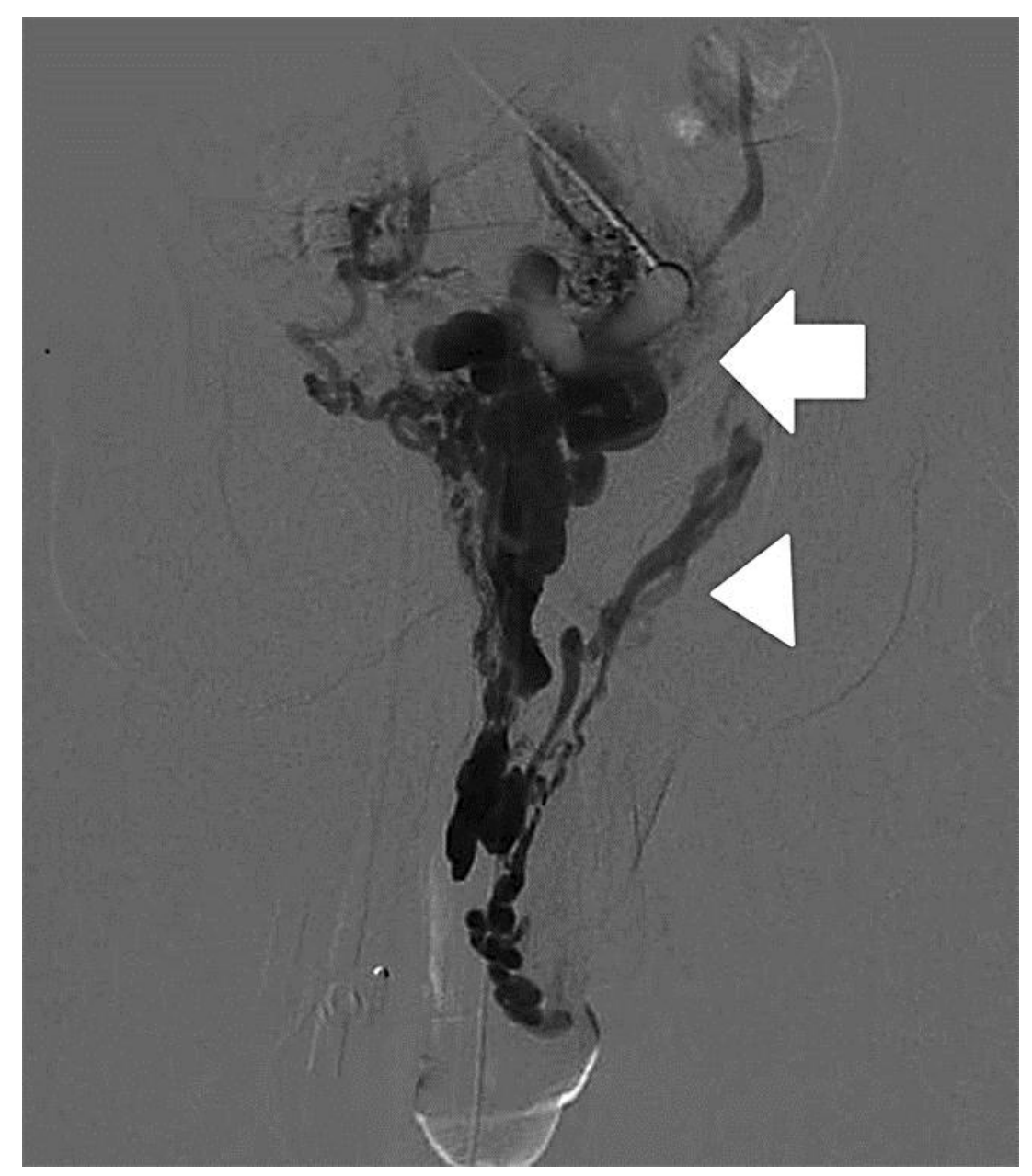

Fig. 3. Portography during balloon occlusion of the blood flow in the IMV demonstrates that the rectal varices (arrow) are supplied with backward blood flow by the IMV and flow into the internal iliac vein (arrowhead). The sclerosant was injected through the balloon catheter into the IMV. 